\title{
Sociology of Postdoctoral Students
}

The closest modern equivalent of the peripatetic mediaeval scholar is, no doubt, the postdoctoral fellow, still largely American by nationality and especially by place of work. The National Academy of Sciences has now published a report of a committee under Dr Richard Curtis in which the growth of postdoctoral education is admirably chronicled (The Invisible University, National Academy of Sciences). One sign of how quickly things have grown is the statement thrt at the California Institute of Technology in 1967-68, postdoctoral fellows outnumbered professors by four to one and that the Harvard Medical School in the same year had more postdoctoral fellows than students.

The beginnings of postdoctoral fellowships lie in the wish of late nineteenth century universities to free young members of staff from teaching commitments. Johns Hopkins and Chicago were among the leaders in the field. The medical schools had a particular incentive to provide places on the staff at which research could be pursued singlemindedly. With the institution of the National Research Council as a peacetime organization immediately after the First World War, that became a formal source of postdoctoral fellowships, chiefly with the objective of encouraging university research. Until the Second World War, the National Research Council in the United States supported roughly 20 per cent of those staying on in academic life after receiving a $\mathrm{PhD}$, at least until other sources of support took up the strain in the mid-thirties.

When the statistics on the new survey were collected, in the spring of 1967, it was estimated that there were 16,000 postdoctoral fellows-a total that includes all United States citizens, even when working abroad, together with forcign nationals in the United States. This implies a doubling of the scale of postdoctoral research between 1960 and 1967 . The most rapid growth has been in chemistry and physics, but there are also signs that the rate of growth is beginning to level off. Indeed, the survey quotes the estimates of the Committee on Physics in Society that the ratio of postdoctoral fellows to faculty members in physics is likely to fall from $0 \cdot 34$ to 0.29 as a result of current difficulties in raising money.

In the United States, most (81 per cent) of the postdoctoral fellows work at academic institutions and 7 per cent are at federal research establishments. Twice as many postdoctoral fellows have a $\mathrm{PhD}$ as have an MD, while 3 per cent of the total population is qualified with both degrees. It seems that $9 \cdot 1$ per cent of the postdoctoral population is made up of people who have spent more than two years on a fellowship, possibly completing work begun during a $\mathrm{PhD}$ course.

The life sciences have more than half the postdoctoral population, while the physical sciences and mathematics have just over a third. Physics, chemistry, biochemistry and medicine are the chief users of postdoctoral fellows. Visitors from abroad are more evenly spread through the various disciplines. It is no surprise that the postdoctoral population is largely concentrated at selected institutions--Harvard has 7 per cent of postdoctoral fellows, half of whom are concentrated in thirteen institutions.
The tendency to stay on after a $\mathrm{PhD}$ has grown steadily. In $1962,8.5$ per cent of all United States PhDs went into postdoctoral fellowships, but by 1967 this percentage had increased to 11.6 per cent. Most of those who stay on-77 per cent-expect to remain in higher education. Only 5 per cent of postdoctoral fellows expect to finish up in the employment of the federal government. The survey points out that several postdoctoral fellows have already turned down faculty appointments at what they consider to be lesser institutions. Postdoctoral fellows are biased against industry. One said that "If I had wanted an industrial job I wouldn't have taken the first doctorate". The survey points out that postdoctoral fellowships tend to spread these people uniformly about the country. The east and west of the United States tend to send young students to the south and west, particularly the latter. The south has a net loss, particularly in physics, but "the west gains from everywhere". The survey has compiled a good deal of evidence to show how postdoctoral fellowships are used as a means of obtaining upward mobility in the academic pecking order. It secms to be established that the reputation of a school determines its success or otherwise in building up a postdoctoral school with high reputation. It is, however, also established that postdoctoral fellowships are a useful means by which young men and women ean change the direction of their interest.

The average length of a postdoctoral fellowship is $1 \cdot 6$ years, and only one-fifth of the total intake seems to stay more than $2 \cdot 3$ years. Foreign and United States postdoctorals spend the same length of time on the job. The longest durations of postdoctoral fellowships are those of biochemists.

The postdoctoral fellows are right in their belief that they can stay on in academic life -72 per cent of former postdoctoral fellows are working in universities and colleges. Universities seem to be divided in their vicws on the usefulness of the postdoctoral system. Some hold that postdoctoral fellows quickly make their presence felt and serve not merely as valuable academic labour but also as examples to other students. The survey says that most postdoctoral fellows "contribute more than they take away", but there seems also to be a feeling that the special circumstances of a postdoctoral appointment detach a man from a proper appreciation of his ultimate responsibility in an academic job. There is also some concern that postdoctoral fellowships may simply be ways of increasing the research output of particular departments without contributing either to the education of the university as a whole or to that of the people concerned.

Foreign postdoctoral fellowships play a prominent part in the American pattern-in 1967, it is estimated that there were 5,626 foreign scientists at American universities with a $\mathrm{PhD}$ from an American or other university. There seems to be a consistent tendency for people from countries with a low GNP per capita to migrate to the United States. The United Kingdom is, however, the largest source of supply, with close on 800 in 1967,200 of whom said they would be returning home. 